\title{
Iodine deficiency in pregnant women living in the South-East of the UK
}

\author{
S. Bath ${ }^{1}$, J. Wright ${ }^{2}$, A. Taylor ${ }^{1}$, A. Walter ${ }^{1}$ and M. P. Rayman ${ }^{1}$ \\ ${ }^{1}$ University of Surrey, Guildford, Surrey GU2 7XH, UK and ${ }^{2}$ Royal Surrey County Hospital, Guildford, Surrey, \\ GU2 $7 X H, U K$
}

Maternal iodine deficiency during pregnancy leads to an inadequate production of thyroid hormone which, because it is required for fetal brain development, can result in reduced IQ, reduced psychomotor development and $\mathrm{ADHD}^{(1)}$. The requirement for iodine is increased from $150 \mu \mathrm{g} / \mathrm{d}$ in adults to $250 \mu \mathrm{g} / \mathrm{d}$ for pregnant women ${ }^{(2)}$. Concerns have been voiced that women in the UK are unable to meet this additional requirement and are therefore at risk of iodine deficiency during pregnancy ${ }^{(3)}$.

A pilot survey of 100 pregnant women at 12 weeks gestation was therefore conducted at the Royal Surrey County Hospital, Guildford. Participants completed a general questionnaire giving details of nutritional supplements, medication, age, parity and eating habits (e.g. vegetarianism) and an FFQ designed to capture the consumption of foods rich in iodine. Participants provided a spot-urine sample; iodine concentration in the urine was determined using inductively coupled plasma MS and creatinine was measured to correct for urinary volume excreted.

Both median urinary iodine concentration $(85 \mu \mathrm{g} / \mathrm{l})$ (see Fig.) and iodine/creatinine ratio $(122.9 \mu \mathrm{g} / \mathrm{l})$ indicated that the group was deficient in iodine according to the WHO criteria ${ }^{(2)}$. Using the estimated iodine excretion in 24-h (based on adjusted iodine/creatinine ratio), only $18 \%$ of the individuals had intakes that satisfied the WHO recommendations for pregnancy ${ }^{(2)}$. Urinary iodine concentration was significantly higher in women taking an iodine-containing supplement $(n$ 42) than in those who did not take such a supplement $(P<0.001)$ (see Fig.) bringing it closer to the optimal value for pregnancy. Ninety-six percent of the women rarely or never consumed iodized salt.

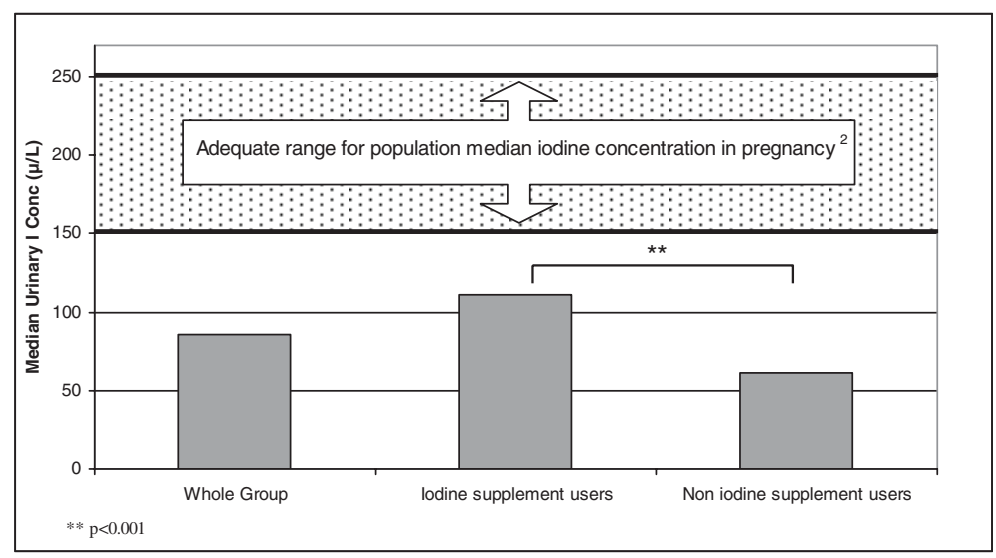

This pilot survey confirms earlier UK work that showed an insufficient intake of iodine in pregnant women ${ }^{(4)}$. The group is classified as mild-to-moderately iodine deficient, which is likely to have implications for the developing fetus. Our findings give cause for concern and challenge the beliefs held by many that iodine intake in the UK is sufficient. Pregnant women should be given advice about dietary sources of iodine and those who habitually have low intakes of iodine-rich foods should ensure that iodine is present in an antenatal supplement. Further studies are needed in different UK regions to confirm these findings in other pregnant women.

S.B. gratefully acknowledges $\mathrm{PhD}$ studentship funding by the Waterloo Foundation and Wassen International.

1. Vermiglio F, Lo Presti VP, Moleti M et al. (2004) Attention deficit and hyperactivity disorders in the offspring of mothers exposed to mild-moderate iodine deficiency: a possible novel iodine deficiency disorder in developed countries. J Clin Endocrinol Metab 89, 6054-6060.

2. Andersson M, de Benoist B, Delange F et al. (2007) Prevention and control of iodine deficiency in pregnant and lactating women and in children less than 2-years-old: conclusions and recommendations of the Technical Consultation. Public Health Nutr 10, 1606-1611.

3. Lazarus JH \& Smyth PP (2008) Iodine deficiency in the UK and Ireland. Lancet 372, 888.

4. Kibirige MS, Hutchison S, Owen CJ et al. (2004) Prevalence of maternal dietary iodine insufficiency in the north east of England: implications for the fetus. Arch Dis Child Fetal Neonatal Ed 89, F436-F439. 